\title{
Guidelines of the Paul-Ehrlich-Society of Chemotherapy, the German Respiratory Diseases Society, the German Infectious Diseases Society and of the Competence Network CAPNETZ for the Management of Lower Respiratory Tract Infections and Community-acquired Pneumonia Summary of the Update 2009
}

Authors

Institutions

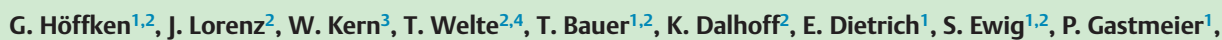
B. Grabein ${ }^{1}$, E. Halle ${ }^{1}$, M. Kolditz ${ }^{2}$, R. Marre ${ }^{3,4}$, H. Sitter ${ }^{5}$

for the Paul-Ehrlich-Society of Chemotherapy

2 for the German Respiratory Diseases Society

for the German Infectious Diseases Society

${ }^{4}$ for the competence network CAPNETZ

5 for the Arbeitsgemeinschaft Wissenschaftlicher Medizinischer Fachgesellschaften AWMF
Bibliography

Dol http://dx.doi.org/ 10.1055/s-0029-1243910

Online-Publikation: 23. 2. 2010

Pneumologie 2010; 64:

149-154 @ Georg Thieme

Verlag KG Stuttgart · New York ISSN 0934-8387

\section{Corresponding author}

Prof. Dr. med. G. Höffken Universitätsklinikum

Carl Gustav Carus Dresden Medizinische Klinik ।

Fetscherstr. 74

01307 Dresden

gert.hoeffken@uniklinikum-

dresden.de

Fachkrankenhaus Coswig

Neucoswiger Str. 21

01640 Coswig

prof.hoeffken@fachkrankenhauscoswig.de

\section{Summary Update 2009 \\ $\nabla$}

This summary of the update of the guidelines for the management of lower respiratory tract infections and community-acquired pneumonia (CAP) provides an overview on the structure and key points provided in this document. It is based on the structure of the Oxford Centre of Evidence Based Medicine.

The update refers to important new insights from studies published by the CAPNETZ and the Bundesgeschäftsstelle für Qualitätssicherung (BQS). Essential new statements as compared to the original 2005 version include the following: 1) treatment of patients with acute exazerbation of COPD (restrictive indications for antimicrobial treatment); 2) preference for the CRB-65 score as tool for the validation of clinical assessment of pneumonia severity; 3) treatment of patients with mild CAP (oral cephalosporins no longer recommended); 4) treatment of patients with moderate CAP (ertapenem as new option in selected cases); 5) treatment of patients with severe CAP (antipseudomonal treatment only rarely indicated; reintroduction of aminoglycosides as agent in combination treatment); 6) reduction of treatment duration; 7) new focus on palliative treatment of patients with CAP.

\section{Definition \\ $\nabla$}

Community-acquired pneumonia is defined as acute infection of lung parenchyma in patients without severe immunosuppression, acquired in the community, excluding those cases with pneumonia within four weeks after hospitalization.

\section{Epidemiology \\ $\nabla$}

Data from the mandatory quality improvement program of the "Bundesgeschäftsstelle für Qualitätssicherung (BQS)" indicate that around 200000 patients are hospitalized with CAP in Germany every year. The overall incidence including outpatients is estimated to reach 400000 to 600000 cases per year. Mortality of hospitalized patients is around $13-14 \%$, whereas it is very low in ambulatory patients with mild CAP $(<1 \%)$.

\section{Microbial spectrum \\ $\nabla$}

Microbial spectrum of CAP varies considerably according to regional, saisonal, epidemiological und demographic factors. Data collected by CAPNETZ confirm $S$. pneumoniae as the most important pathogen of CAP [1] ( $\bullet$ Table 1 ).

Antimicrobial treatment of patients with CAP is empirical in most instances. Factors such as age, comorbidity, antimicrobial pretreatment etc. are associated with particular pathogens or microbial spectra which should be considered in the selection of adequate empiric initial antimicrobial treatment. CAP through $P$. aeruginosa requires an antimicrobial treatment most different from any other etiology, however, it was found to be rare in Germany.

\section{Microbial resistance $\nabla$}

Microbial resistance rates have increased in Europe and worldwide, including pathogens such as S. pneumoniae or $H$. influenzae. In Germany, pneumococcal penicillin-resistance is infrequent and mostly intermediate, thus penicillin treatment of patients with pneumococcal CAP continues to be a safe option. However, pneumococcal 
Table 1 Frequency of pathogens of CAP in Germany according to data from CAPNETZ.

\begin{tabular}{|l|l|}
\hline Frequency & Pathogen \\
very frequent $(40-50 \%)$ & S. pneumoniae \\
\hline frequent $(5-10 \%)$ & H. influenzae \\
& M. pneumoniae \\
& Enterobacteriaceae (GNEB) \\
& Respiratory viruses: \\
& RS-Virus, adenovirus, influenzavirus \\
\hline rare $(<5 \%)$ & Legionella spp. \\
& S. aureus \\
& P. aeruginosa \\
& C. pneumoniae \\
\hline about $20-25 \%$ & etiology unknown \\
\hline
\end{tabular}

macrolide resistance is of concern at least in patients with moderate to severe CAP.

\section{Microbial investigation \\ $\nabla$}

The amount of microbial investigation required depends on the severity of CAP. Recommendations for empiric initial antimicrobial treatment are based on local and national epidemiology.

\section{Clinical symptoms and findings in lower respiratory tract infection (LRTI)}

The diagnosis of CAP cannot be firmly made on clinical grounds alone. Chest radiography remains the mainstay to differentiate LRTI and CAP. LRTIs include the following conditions which should be differentiated whenever possible: acute bronchitis, acute exacerbation of COPD, and influenza infection (Recommendation B).

\section{Management of LRTI \\ $\nabla$}

Patients with acute bronchitis without obstructive lung disease do not require antimicrobial treatment but only symptomatic measures [2] (Recommendations A).

Outside a pandemic, clinical diagnosis of influenza infection is not reliable. Antiviral treatment is costly, and excessive prescription represents a key resistance driver. On the other hand, benefits of treatment are limited (reduction of morbidity by around 1.5 days). Therefore, patients with symptoms of saisonal influenza infection should not generally receive antiviral agents. Such treatment may be considered in high risk patients and in those presenting with severe CAP. (Recommendation D).

\section{Acute exacerbation of COPD \\ $\nabla$}

Around one half of episodes of acute exacerbations are thought to have an infectious etiology, mostly viral. The most frequent bacterial pathogens include $H$. influenzae, S. pneumoniae, M. catarrhalis, Enterobacteriaceae (GNEB) and P. aeruginosa.

Investigation of sputum is recommended only in patients with severe courses, frequent exacerbations ( $>2$ per year) or if (multi) resistant pathogens are suspected.
The recommendations for the management of acute exacerbations follow a new approach based primarily on the severity of the acute exacerbation rather than that of COPD since the latter may be difficult to determine confidently at presentation of the patient. Following this structure, patients with severe COPD may present with mild exacerbation as well as the other way round. Indications for antimicrobial treatment are still not clearly established. The key indication for antimicrobial treatment is thought to be an increase of dyspnea and the presence of purulent sputum together with moderate to severe COPD. This view is based on the Stockley criteria rather than the traditional Anthonisen criteria.

Thus, in ambulatory patients with mild exacerbations, antimicrobial treatment is recommended only in patients with purulent sputum and (probably) severe COPD. Hospitalized patients should also receive antimicrobial treatment in case of purulent sputum [3]. An alternative approach is based on the determination of procalcitonin (PCT). Patients with $\mathrm{PCT}<0,1 \mathrm{ng} / \mathrm{ml}$ usually do not require antimicrobial treatment. All patients presenting with severe exacerbations treated at the ICU should receive antimicrobial treatment (Recommendation B).

In ambulatory patients with mild exacerbations, first line treatment is an aminopenicillin without betalactamase inhibitor. Alternatives include macrolides and doxycyclin (Recommendation C).

In hospitalized patients with moderate to severe exacerbations, an aminopenicillin with betalactamase inhibitor or a parenteral cephalosporin II or III is recommended. Alternatives include respiratory fluoroquinolones (Recommendation C).

Patients known to be colonized with P. aeruginosa, with bronchiectasis or requiring ventilatory support should receive an antipseudomonal treatment (acylureidopenicillin plus betalactamase inhibitor, antipseudomonal carbapenem, antipseudomonal cephalosporin or antipseudomonal fluoroquinolone) (Recommendation C).

Treatment duration is generally 7 days. Even shorter treatment duration is effective in some indications and antimicrobial agents (macrolides, fluoroquinolones) (Recommendation C).

\section{Management of CAP}

$\nabla$

\section{Severity stratification of CAP and treatment setting}

Risk groups include: 1) mild CAP with or without specific individual risk factors, preferably treated as outpatients; 2 ) moderate CAP, hospitalized and treated at the regular ward; 3) severe CAP, admitted at the ICU or intermediate care unit.

\section{Hospital admission \\ $\nabla$}

The decision to hospitalize a patient with CAP remains a clinical decision based on severity assessment and other medical and nonmedical considerations. However, CRB-65 should be used as tool to validate pneumonia severity assessment $[4,5]$. Hospitalization should be considered in all patients with a CRB-65 score $>0(\bullet$ Table 2$)$. Age alone is not an indication to hospitalize. 
Table 2 CRB-65-Score

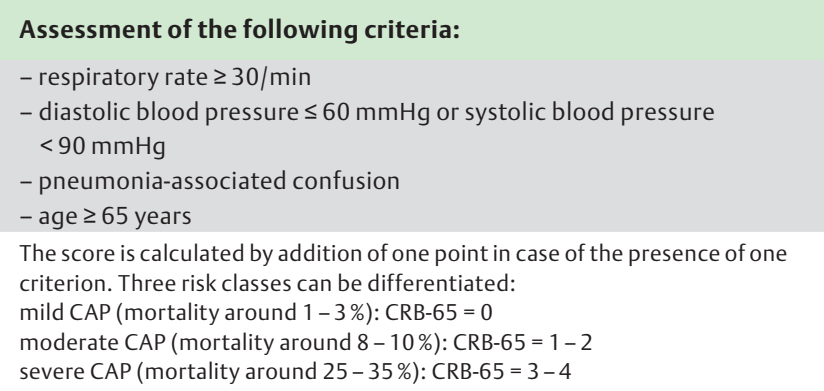

Table 3 Modified ATS-criteria for severe community-acquired pneumonia.

"Major"-criteria, at admission or during follow up
(positive in case of the presence of 1 of 2 criteria)
1. Requirement for intubation and mechanical ventilation
2. Requirement for vasopressors $>4 \mathrm{~h}$ despite fluid replacement
(septic shock)
"Minor"-criteria, at admission
(positive in case of the presence of 2 of 3 criteria)
1. acute respiratory failure $\left(\mathrm{PaO}_{2} / \mathrm{F}_{1} \mathrm{O}_{2}<250\right.$ )
2. multilobar infiltrates on chest radiograph
3. systolic blood pressure $<90 \mathrm{mmHg}$

\section{Decision to admit at the ICU or intermediate care unit}

The decision to admit at the ICU or another unit providing intensified treatment (e.g. intermediate care unit) is also a clinical decision depending on local facilities and ICU admission policies. The modified ATS-score is recommended as a tool to validate clinical judgment ( $\bullet$ Table 3 ).

\section{Mild CAP}

$\nabla$

Patients with mild CAP are further differentiated in two groups: patients with and without specific individual risk factors. Such risk factors include: previous antimicrobial treatment, comorbidity, residence in nursing home (Recommendation A).

Clinical assessment includes history, physical examination, chest radiography and basic laboratory parameters. Microbial investigation should be considered only in the subgroup with risk factors (Recommendation A).

Recommendations for initial empiric antimicrobial treatment are given in Table 4 and $\bullet$ Table 5 (Recommendation A).

Antimicrobial treatment may be stopped $48-72 \mathrm{~h}$ after clinical improvement but not earlier than after 5 days. On the other hand, treatment duration beyond 7 days is usually not required (Recommendation A).

Ambulatory treatment requires at least a stable social background and normal gastric resorption. A clinical reevaluation after $48(-72)$ hours is mandatory. In any doubt, short term hospitalization should be considered. (Recommendation B ).
Table 4 Recommendations for empiric initial antimicrobial treatment in patients with mild CAP without risk factors.

\begin{tabular}{|c|c|c|}
\hline Agents & Daily dosage & Treatment duration \\
\hline \multicolumn{3}{|c|}{ Treatment of choice } \\
\hline $\begin{array}{l}\text { aminopenicillin } \\
\text { - amoxicillin }\end{array}$ & $\begin{array}{l}\geq 70 \mathrm{~kg}: 3 \times 1 \text { g orally } \\
<70 \mathrm{~kg}: 3 \times 0,75 \text { g orally }\end{array}$ & $5-7$ days \\
\hline Alternatives & & \\
\hline $\begin{array}{l}\text { macrolide } \\
\text { - azithromycin } \\
\text { - clarithromycin } \\
\text { - roxithromycin }\end{array}$ & $\begin{array}{l}1 \times 500 \mathrm{mg} \text { orally } \\
2 \times 500 \mathrm{mg} \text { orally } \\
1 \times 300 \mathrm{mg} \text { orally }\end{array}$ & $\begin{array}{l}3 \text { days } \\
5-7 \text { days } \\
5-7 \text { days }\end{array}$ \\
\hline or & & \\
\hline $\begin{array}{l}\text { tetracyclin } \\
\text { - doxycyclin }\end{array}$ & $\begin{array}{l}1 \times 200 \mathrm{mg} \text { orally initially, } \\
\geq 70 \mathrm{~kg}: 1 \times 200 \mathrm{mg} \\
<70 \mathrm{~kg}: 1 \times 100 \mathrm{mg}\end{array}$ & 5-7 days \\
\hline
\end{tabular}

Table 5 Recommendations for empiric initial antimicrobial treatment in patients with mild CAP with risk factors.

\begin{tabular}{|c|c|c|}
\hline Agents* & Daily dosages* & Treatment duration \\
\hline \multicolumn{3}{|l|}{ Treatment of choice } \\
\hline \multicolumn{3}{|l|}{ betalactam } \\
\hline $\begin{array}{l}\text { - amoxicillin/ } \\
\text { clavulanic acid }\end{array}$ & $2 \times 875 / 125 \mathrm{mg}$ orally & $5-7$ days \\
\hline - sultamicillin & $2 \times 0,75$ g orally & 5-7 days \\
\hline \multicolumn{3}{|l|}{ Alternatives } \\
\hline \multicolumn{3}{|l|}{ fluoroquinolone ${ }^{* *}$} \\
\hline - levofloxacin & $1 \times 500 \mathrm{mg}$ orally & 5-7 days \\
\hline - moxifloxacin & $1 \times 400 \mathrm{mg}$ orally & $5-7$ days \\
\hline
\end{tabular}

\section{Management of CAP in the hospital}

Clinical assessment includes history and physical examination, chest radiography, laboratory assessment (including CRP or PCT) as well as blood gase analysis or at least pulse oxymetry (Recommendation $\mathrm{A}$ ).

Antimicrobial treatment should be initiated as soon as possible and should not be delayed by any diagnostic measures (Recommendation B).

Adjuvant treatment includes prophylactic low dose heparin and early mobilisation. Oxygen should be supplemented in patients with hypoxemia (Recommendation A).

Discharge from hospital should be considered after confirmation of treatment response. Stability criteria include: stable vital signs, ability to eat, safe oral drug intake, and normal mental status. The social setting should be considered additionally. Clinical follow up should include a reinvestigation 3 to 7 days after discharge (Recommendation B).

A follow up chest radiography not earlier than 14 days after the end of treatment in order to confirm the diagnosis and exclude malignancy is recommended, particularly in active smokers, elderly patients (> 65 years) and those with severe comorbidity. 


\section{Management of CAP at the ward}

The clinical relevance of microbial investigation in hospitalized patients with moderate CAP is unsettled. The following investigations are recommended: two sets of blood cultures, diagnostic thoracocentesis and analysis of pleural effusion, L. pneumophilaantigentest in urine as well as sputum in patients with purulent sputum, without antimicrobial pretreatment, provided that the facilities for immediate processing are established (Recommendation $\mathrm{B})$.

Recommendations for initial empiric antimicrobial treatment are given in Table $6[6,7]$ (Recommendation A).

Antimicrobial treatment should initially be administered intravenously. Fluoroquinolones have excellent bioavailability and may be given orally. Macrolides may be given orally as part of a combination treatment with betalactams (Recommendation B). Antimicrobial treatment should be designed as sequential treatment. Oral treatment is possible when clinical stability criteria are met (Recommendation $\mathrm{A}$ ).

Antimicrobial treatment may be stopped $48-72 \mathrm{~h}$ after clinical improvement but not earlier than after 5 days. On the other hand, treatment duration beyond 7 days is usually not required (Recommendation A).

Table 6 Recommendations for empiric initial antimicrobial treatment in hospitalized patients with moderate CAP.

\begin{tabular}{|c|c|c|}
\hline Agents & Daily dosages & Treatment duration \\
\hline $\begin{array}{l}\text { betalactam } \\
\text { - amoxicillin/clavulanic acid } \\
\text { - ampicillin/sulbactam } \\
\text { - cefuroxim } \\
\text { - ceftriaxon } \\
\text { - cefotaxim } \\
\text { with or without macrolide }\end{array}$ & $\begin{array}{l}3 \times 2,2 \mathrm{~g} \text { i. } v \\
3 \times 3,0 \mathrm{~g} \text { i. } . \\
3 \times 1,5 \mathrm{~g} \text { i. } . \\
1 \times 2,0 \mathrm{~g} \text { i. } . \\
3 \times 2,0 \mathrm{~g} \text { i. }\end{array}$ & $\begin{array}{l}5-7 \text { days } \\
5-7 \text { days } \\
5-7 \text { days } \\
5-7 \text { days } \\
5-7 \text { days } \\
5-7 \text { days }\end{array}$ \\
\hline $\begin{array}{l}\text { or* }^{*} \\
\text { fluoroquinolone } \\
\text { - levofloxacin } \\
\text { - moxifloxacin }\end{array}$ & $\begin{array}{l}1 \times 500 \mathrm{mg} \text { i. } v . \\
1 \times 400 \mathrm{mg} \text { i. } .\end{array}$ & $\begin{array}{l}5-7 \text { days } \\
5-7 \text { days }\end{array}$ \\
\hline $\begin{array}{l}\text { or in selected patients** } \\
\text { carbapenem } \\
\text { - ertapenem } \\
\text { with or without macrolide }\end{array}$ & $1 \times 1,0 \mathrm{~g}$ i. $v$. & $\begin{array}{l}5-7 \text { days } \\
5-7 \text { days }\end{array}$ \\
\hline \multicolumn{3}{|c|}{$\begin{array}{l}{ }^{*} \text { in case of previous antimicrobial treatment within the last three months a } \\
\text { change of agent class is recommended. } \\
{ }^{* *} \text { patients with risk factors for enterobacteriaceae including ESBL } \\
\text { (except } P \text {. aeruginosa) and patients with previous antimicrobial treatment } \\
\text { with penicillins or cephalosporins. }\end{array}$} \\
\hline
\end{tabular}

\section{Management of severe CAP (ICU or intermediate care unit)}

Patients with severe CAP are further differentiated in two groups: those with and without risk factors for pneumonia through $P$. aeruginosa. Pneumonia through $P$. aeruginosa is rare in Germany. Risk factors include structural lung disease, frequent antimicrobial pretreatment, frequent prior hospitalization (Recommendation C).

Microbial investigation should be comprehensive since diagnostic yield and relevance are higher in these patients. The following investigations are recommended: two sets of blood cultures, cultures of sputum or tracheobronchial aspirate, pleural effusion, $L$. pneumophila-antigentest in urine, bronchoscopy (BAL, PSB).
Table 7 Recommendations for empiric initial antimicrobial treatment in patients with severe CAP without risk factors for $P$. aeruginosa.

\begin{tabular}{|c|c|c|}
\hline Agents & Daily dosage & Treatment duration \\
\hline \multicolumn{3}{|l|}{ Treatment of choice ${ }^{* *}$} \\
\hline $\begin{array}{l}\text { betalactam } \\
\text { - piperacillin/tazobactam } \\
\text { - ceftriaxon } \\
\text { - cefotaxim } \\
\text { - ertapenem } \\
\text { plus macrolide }\end{array}$ & $\begin{array}{l}3 \times 4,5 \mathrm{~g} \text { i. } v \\
1 \times 2,0 \mathrm{~g} \text { i. } \\
3 \times 2,0 \mathrm{~g} \text { i. } . \\
1 \times 1,0 \mathrm{~g} \text { i. }\end{array}$ & $\begin{array}{l}8-10 \text { days } \\
8-10 \text { days } \\
8-10 \text { days } \\
8-10 \text { days } \\
8-10 \text { days }\end{array}$ \\
\hline \multicolumn{3}{|l|}{ Alternatives* } \\
\hline $\begin{array}{l}\text { fluorquinolone }{ }^{* * *} \\
\text { - levofloxacin } \\
\text { - moxifloxacin }\end{array}$ & $\begin{array}{l}2 \times 500 \mathrm{mg} \text { i. v. } \\
1 \times 400 \mathrm{mg} \text { i. } \mathrm{v} .\end{array}$ & $\begin{array}{l}8-10 \text { days } \\
8-10 \text { days }\end{array}$ \\
\hline \multicolumn{3}{|c|}{$\begin{array}{l}\text { *in case of previous antimicrobial treatment within the last three months a } \\
\text { change of agent class used is recommended. } \\
*^{* *} \text { patients with risk factors for enterobacteriaceae including ESBL } \\
\text { (except } P \text {. aeruginosa) and patients with previous antimicrobial treatment } \\
\text { with penicillins or cephalosporins. } \\
* * * \text { patients with septic shock and/or invasive ventilation must receive an } \\
\text { initial empiric combination treatment with a betalactam. } \\
* * * * \text { Initial parenteral administration is recommended. }\end{array}$} \\
\hline
\end{tabular}

Table 8 Recommendations for empiric initial antimicrobial treatment in patients with sevre CAP with risk factors for P.aeruginosa.

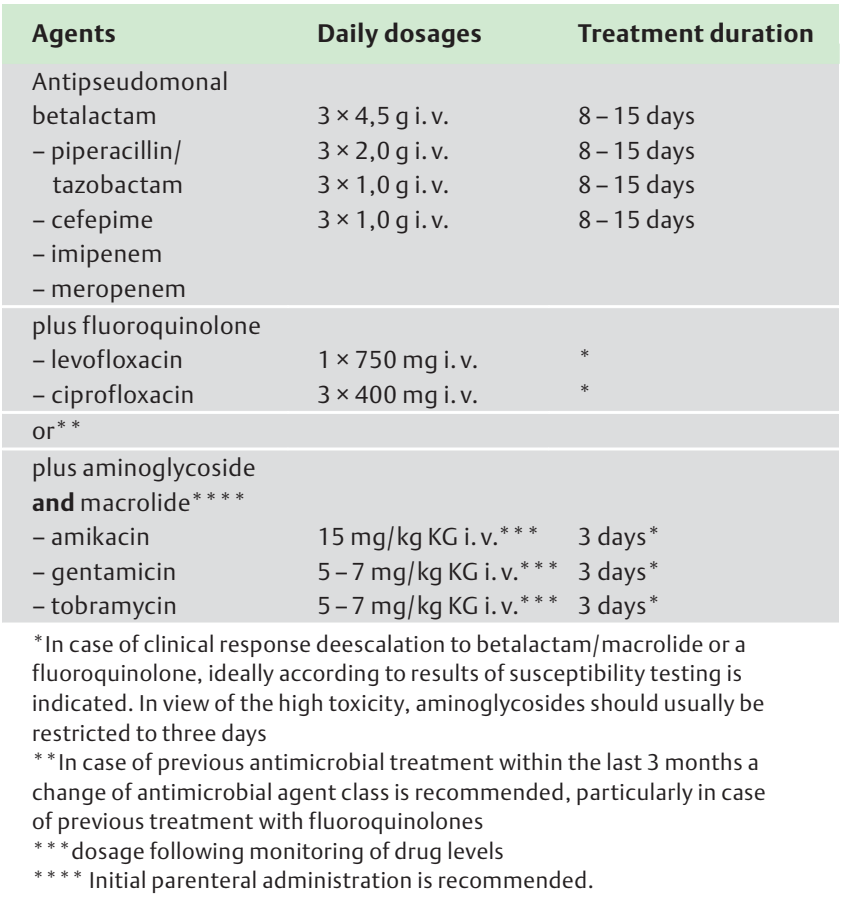

However, whether etiological diagnosis with or without bronchoscopy has a prognostic impact is unknown (Recommendation B).

Inadequate initial antimicrobial treatment and monotherapy may be associated with an excess mortality. Therefore, combination treatment including a broad spectrum betalactam with a non-betalactam is recommended at least in all patients with septic shock (Recommendation B).

Recommendations for initial empiric antimicrobial treatment are given in $\bullet$ Table 7 and $\bullet$ Table 8 [8] (Recommendation B).

Treatment duration should be $8-10$ days or at least 5 days after clinical stability. In CAP through $P$. aeruginosa, treatment duration should be $8-15$ days (Recommendation $\mathrm{B}$ ). 


\section{Treatment failure}

$\nabla$

Treatment failure is differentiated in two subgroups: primary treatment failure (progressive pneumonia) and slowly responding pneumonia [9]. Progressive pneumonia is defined as clinical deterioration with development of respiratory failure and/or severe sepsis or septic shock despite initial empiric antimicrobial treatment. Slowly responding pneumonia is defined as failure to achieve clinical stability after $72 \mathrm{~h}$ of initial empiric antimicrobial treatment and/or failure of radiographic resolution. Treatment failures occur in $5-10 \%$ of hospitalized patients with CAP. These may be due to infectious as well as noninfectious reasons; around $2 / 3$ of cases have infectious reasons.

The diagnostic assessment of treatment failure is complex. It should include a careful history, physical examination, reevaluation of epidemiological data and antimicrobial treatment selection, dosage and duration, as well as consideration of non-infectious conditions. This may require additional thoracic imaging, exclusion of severe immunsuppression and extrapulmonary infections. Additional microbial investigations may be indicated (Recommendation B).

Patients with progressive pneumonia are at high risk of death and should be subject to intensified treatment, including empiric second-line parenteral antimicrobial combination treatment. Treatment options may include the initiation of adequate broad antimicrobial combination treatment in case of initially inadequate treatment or coverage of rare or resistant pathogens (e.g. P. aeruginosa, S. aureus (MRSA), Legionella spp. and anaerobes), Coverage of $S$. pneumoniae should be preserved (Recommendation B).

\section{Aspiration pneumonia}

$\nabla$

Aspiration is a risk factor for enterobacteriaceae (GNEB) and probably anaerobes and antimicrobial treatment should cover these pathogens (usually broad spectrum betalactam with betalactamase inhibitor. Alternatives include a combination of a parenteral cephalosporin II or III with clindamycin, moxifloxacin or a carbapenem (Recommendation D).

\section{Lung abscess}

Mixed etiologies including two or more pathogens are frequently present, and also anaerobes are frequently involved. Other etiologies such as fungi (e.g. semi-invasive necrotizing aspergillosis) and Echinococcus spp. have to be taken into account.

Bronchoscopy is usually required to confirm pus drainage and exclude potential bronchial obstruction. In addition, a CT-scan is recommended (Recommendation C).

Antimicrobial treatment of lung abscess includes an aminopenicillin with betalactamase inhibitor or a parenteral cephalosporin II or III with clindamycin (Recommendation B).

\section{Targeted treatment \\ 7}

Fluoroquinolones are the agents of choice in CAP through Legionella spp. Mycoplasma pneumoniae and Chlamydophilia pneumoniae are sensitive to macrolides, fluoroquinolones and tetracyclines. The treatment of choice for Coxiella burnetii ( $\mathrm{Q}$-fever) is doxycycline.

MRSA in patients with CAP may represent h-MRSA or c-MRSA. The latter is still very rare in Germany. Confirmed MRSA-pneumonia may be treated with vancomycin (in case of MIC $<2 \mathrm{mg} / \mathrm{l}$ and normal renal function) or with linezolid. CAP through methicillin-sensible $S$. aureus (MSSA) should be treated with flucloxacillin.

\section{Prevention of CAP \\ $\nabla$}

Studies and metaanalyses confirm protection from influenza infection (reduction of influenza associated LRTI and pneumonia, hospitalisation rates and mortality) using influenza vaccine. Absolute risk reduction is two to five times higher in high-risk patients as compared to elderly healthy individuals. In line with the recommendations of STIKO, a yearly vaccination against influenza is recommended in all individuals at increased risk (Recommendation A).

Likewise, the body of data indicates that 23-valent capsular pneumococcal polysaccharide vaccine effectively reduces invasive pneumococcal disease. The effect is lower in elderly individuals. In line with the recommendations of STIKO, pneumococcal polysaccaride vaccination is recommended for all individuals at increased risk for pneumococcal disease (Recommendation A). Cigarette smoking is an important risk factor for CAP. Cessation of cigarette smoking should be propagated (Recommendation A).

\section{CAP as terminal event in elderly and severely disabled patients \\ $\nabla$}

Changes in treatment goals towards palliative treatment may be applied in many ways, e.g. by restriction or limitation of medical interventions and monitoring. Decisions about changes in treatment goals must not follow a hidden agenda but should be discussed, communicated and documented in a transparent way. The indication for palliative treatment is dependent on the will of the patient. Careful exploration of the declared intention, wishes and demands of the patient is mandatory. Patient testimonies may be very helpful to explore the will of a comatose or confused patient; otherwise, the legal social worker has to represent the patient. In critical patients, it may be necessary to assess the indication for palliative treatment repeatedly during treatment. Palliative treatment includes palliative medication, adequate nursing, and personal dedication. The most frequent symptoms which are target for palliative medication include dyspnea, fever, cough, malaise, pain and neuropsychiatric symptoms such as confusion, agitation and anxiety [10]. 


\section{Selected References}

1 Von Baum H, Ewig S, Marre R et al. Community-acquired Legionella pneumonia: new insights from the German competence network for community acquired pneumonia. Clin Infect Dis 2008; 46: 1356-1364

2 Gonzales R, Steiner JF, Lum A, Barrett PH Jr. Decreasing antibiotic use in ambulatory practice: impact of a multidimensional intervention on the treatment of uncomplicated acute bronchitis in adults. JAMA 1999; 281: $1512-1519$

3 Stockley RA, O'Brien C, Pye A, Hill SL. Relationship of sputum color to nature and outpatient management of acute exacerbations of COPD. Chest 2000; 117: 1638 - 1645

4 Lim WS, van der Eerden MM, Laing $R$ et al. Defining community acquired pneumonia severity on presentation to hospital: an international derivation and validation study. Thorax 2003; 58: 377-382

5 Bauer TT, Ewig S, Marre R et al. CRB-65 predicts death from community-acquired pneumonia. J Intern Med 2006; 260: 93 -101
6 Vetter N, Cambronero-Hernandez E, Rohlf J et al. A prospective, randomized, double-blind multicenter comparison of parenteral ertapenem and ceftriaxone for the treatment of hospitalized adults with community-acquired pneumonia. Clin Ther 2002; 24: 1770-1785

7 Yakovlev SV, Stratchounski LS, Woods GL et al. Ertapenem versus cefepime for initial empirical treatment of pneumonia acquired in skilledcare facilities or in hospitals outside the intensive care unit. Eur J Clin Microbiol Infect Dis 2006; 25: 633-641

8 Rodriguez A, Mendia A, Sirvent JM et al. Combination antibiotic therapy improves survival in patients with community-acquired pneumonia and shock. Crit Care Med 2007; 35: 1493 - 1498

9 Arancibia F, Ewig S, Martinez JA et al. Antimicrobial treatment failures in patients with community-acquired pneumonia: Causes and prognostic implications. Am J Respir Crit Care Med 2000; 162: 154-160

10 Ewig $S$ für die BQS-Arbeitsgruppe Pneumonie. Therapiebegrenzung: Herausforderung für die ärztliche Urteilskraft. Dt Ärztebl 2008; 105: A878 - A879 